\title{
Letter to the Editor: Is There an Obesity Paradox in Diabetic Patients Undergoing Subtotal Gastrectomy for Gastric Cancer?
}

I encountered and have read the article by Kwon et al. ${ }^{1)}$ with great interest. I appreciate the effort involved in this study to evaluate the effect of weight status on mortality in patients with type 2 diabetes (T2DM) who underwent subtotal gastrectomy for gastric cancer. This type of research is needed because of the lack of evidence for the effect of weight status in operable gastric cancer, although the obesity paradox is observed in various diseases. The topic of the study is also relevant in regard to the increasing rate of gastric cancer surgery in elderly individuals and the related growing frequency of obesity in the population. Herein, we have some suggestions for the study.

My main suggestion is regarding the variable selection in the multivariable Cox proportional hazards regression models used to estimate adjusted hazard ratios for investigating the association between weight status and all-cause mortality. Several covariates can mediate the relationship between the body mass index and mortality, and the relationship can be falsely significant after adjustment for covariates. Instead of total cholesterol level and blood pressure, dyslipidemia and hypertension would be more appropriate covariates. Moreover, since the Charlson comorbidity index included hypertension and diabetes, total cholesterol level and blood pressure were not necessary. The glycated hemoglobin and fasting plasma glucose levels are redundant variables.

Furthermore, several key prognostic indicators for patients with gastric cancer were omitted from the analysis, including surgical outcome and cancer recurrence. Obesity has generally been regarded as a poor prognostic factor for the intraoperative and postoperative outcomes following gastric can$\operatorname{cer}^{2,3}$. One of the reasons for this is higher local recurrence because complete lymph node dissection is difficult in gastric cancer patients with obesity ${ }^{2,4)}$. However, recent studies of laparoscopic distal gastrectomy show that obesity does not affect surgical outcomes ${ }^{5,6}$. In this paper, there is no patient data after surgery, except all-cause mortality. In my view, it is difficult to reach a conclusion without such information.

In this study ${ }^{1)}$, the obesity paradox was observed only in ages $<65$ years, not in ages $\geq 65$ years. This finding does not correspond with earlier studies that reported a conservative obesity paradox among the elderly community ${ }^{7-9}$. The author assumed that the reason for different results according to age group was because of higher perioperative mortality in the older group compared with the younger group. Because there is no surgery related data in the paper, I cannot conclusively decide whether the supposition is correct. Stomach cancer and subtotal gastrectomy often induce weight loss, and the T2DM status tends to improve after subtotal gastrectomy ${ }^{1)}$. Given these complex interactions, I think the results of the obesity paradox in patients with T2DM undergoing subtotal gastrectomy for cancer may differ from the general population.

Despite these limitations in methodology, I think that this is a meaningful study. The obesity paradox is a highly debatable topic. It would not be possible to get a complete answer to this question through the present research. Further research should be conducted to identify the relation between weight status and gastric cancer depending on the age groups for the population of patients with T2DM undergoing subtotal gastrectomy for cancer.

Conflicts of Interest Disclosures: The researcher claims no conflicts of interest.

\footnotetext{
Jongkyoung Choi

Department of Internal Medicine, National Medical Center, Seoul, Korea
}

Corresponding Author: Jongkyoung Choi, MD

Department of Internal Medicine, National Medical Center, 245

Eulji-ro, Jung-gu, Seoul 04564, Korea

Tel: +82-2-2260-7232, Fax: +82-2-2260-7055

E-mail: cjk@nmc.or.kr

Received: August 30, 2017

Revised: August 30, 2017

Accepted: September 9, 2017 


\section{REFERENCES}

1. Kwon Y, Kim KJ, Roh YK, Park YG, Park S, Cho KH. Weight status and all-cause mortality in older adults: a study of patients with type 2 diabetes undergoing subtotal gastrectomy for cancer. Ann Geriatr Med Res 2017;21:70-7.

2. Shimada S, Sawada N, Ishiyama Y, Nakahara K, Maeda C, Mukai $\mathrm{S}$, et al. Impact of obesity on short- and long-term outcomes of laparoscopy assisted distal gastrectomy for gastric cancer. Surg Endosc 2017 Jun 27 [Epub]. https://doi.org/10.1007/s00464-0175684-9.

3. Wu XS, Wu WG, Li ML, Yang JH, Ding QC, Zhang L, et al. Impact of being overweight on the surgical outcomes of patients with gastric cancer: a meta-analysis. World J Gastroenterol 2013; 19:4596-606.

4. Dhar DK, Kubota H, Tachibana M, Kotoh T, Tabara H, Masunaga $\mathrm{R}$, et al. Body mass index determines the success of lymph node dissection and predicts the outcome of gastric carcinoma patients. Oncology 2000;59:18-23.

5. Chen K, Pan Y, Zhai ST, Cai JQ, Chen QL, Chen DW, et al.
Laparoscopic gastrectomy in obese gastric cancer patients: a comparative study with non-obese patients and evaluation of difference in laparoscopic methods. BMC Gastroenterol 2017; 17:78.

6. Jung JH, Ryu SY, Jung MR, Park YK, Jeong O. Laparoscopic distal gastrectomy for gastric cancer in morbidly obese patients in South Korea. J Gastric Cancer 2014;14:187-95.

7. Kim NH, Lee J, Kim TJ, Kim NH, Choi KM, Baik SH, et al. Body mass index and mortality in the general population and in subjects with chronic disease in Korea: A Nationwide Cohort Study (2002-2010). PLoS One 2015;10:e0139924.

8. Wang YF, Tang Z, Guo J, Tao LX, Liu L, Li HB, et al. BMI and BMI changes to all-cause mortality among the elderly in Beijing: a 20-year Cohort Study. Biomed Environ Sci 2017;30: 79-87.

9. Yamazaki K, Suzuki E, Yorifuji T, Tsuda T, Ohta T, IshikawaTakata $\mathrm{K}$, et al. Is there an obesity paradox in the Japanese elderly population? A community-based cohort study of 13-280 men and women. Geriatr Gerontol Int 2016 Aug 4 [Epub]. https://doi.org/ 10.1111/ggi.12851. 